\title{
Lidocaine combined with magnesium sulfate preserved hemodynamic stability during general anesthesia without prolonging neuromuscular blockade: a randomized, double-blind, controlled trial
}

\author{
Waynice N Paula-Garcia ${ }^{1 *}$ (D, Gustavo H Oliveira-Paula², Hans Donald de Boer ${ }^{3}$ and Luis Vicente Garcia ${ }^{1}$
}

\begin{abstract}
Background: Lidocaine and magnesium sulfate have become increasingly utilized in general anesthesia. The present study evaluated the effects of these drugs, isolated or combined, on hemodynamic parameters as well as on the cisatracurium-induced neuromuscular blockade (NMB).

Methods: At a university hospital, 64 patients, ASA physical status I and II, undergoing elective surgery with similar pain stimuli were randomly assigned to four groups. Patients received a bolus of lidocaine and magnesium sulfate before the tracheal intubation and a continuous infusion during the operation as follows: $3 \mathrm{mg} \cdot \mathrm{kg}^{-1}$ and 3 mg. $\mathrm{kg}^{-1} \cdot \mathrm{h}^{-1}$ (lidocaine - L group), $40 \mathrm{mg} \cdot \mathrm{kg}^{-1}$ and $20 \mathrm{mg} \cdot \mathrm{kg}^{-1} \cdot \mathrm{h}^{-1}$ (magnesium - M group), equal doses of both drugs (magnesium plus lidocaine - ML group), and an equivalent volume of isotonic solution (control - C group). Hemodynamic parameters and neuromuscular blockade features were continuously monitored until spontaneous recovery of the train of four (TOF) ratio (TOFR $>0.9$ ).

Results: The magnesium sulfate significantly prolonged all NMB recovery features, without changing the speed of onset of cisatracurium. The addition of lidocaine to Magnesium Sulfate did not influence the cisatracurium neuromuscular blockade. A similar finding was observed when this drug was used alone, with a significantly smaller fluctuation of mean arterial pressure (MAP) and heart rate (HR) measures during anesthesia induction and maintenance. Interestingly, the percentage of patients who achieved a TOFR of 90\% without reaching T1-95\% was higher in the $M$ and $M L$ groups. Than in the $C$ and $L$ groups. There were no adverse events reported in this study.

* Correspondence: wgarcia@fmrp.usp.br

${ }^{1}$ Department of Orthopedics and Anesthesiology, Faculty of Medicine of Ribeirao Preto, University of São Paulo, Ribeirão Preto, SP 14049900, Brazil

Full list of author information is available at the end of the article

(c) The Author(s). 2021 Open Access This article is licensed under a Creative Commons Attribution 4.0 International License, which permits use, sharing, adaptation, distribution and reproduction in any medium or format, as long as you give appropriate credit to the original author(s) and the source, provide a link to the Creative Commons licence, and indicate if changes were made. The images or other third party material in this article are included in the article's Creative Commons licence, unless indicated otherwise in a credit line to the material. If material is not included in the article's Creative Commons licence and your intended use is not permitted by statutory regulation or exceeds the permitted use, you will need to obtain permission directly from the copyright holder. To view a copy of this licence, visit http://creativecommons.org/licenses/by/4.0/ The Creative Commons Public Domain Dedication waiver (http://creativecommons.org/publicdomain/zero/1.0/) applies to the data made available in this article, unless otherwise stated in a credit line to the data. 


\begin{abstract}
(Continued from previous page)
Conclusion: Intravenous lidocaine plays a significant role in the hemodynamic stability of patients under general anesthesia without exerting any additional impact on the NMB, even combined with magnesium sulfate. Aside from prolonging all NMB recovery characteristics without altering the onset speed, magnesium sulfate enhances the TOF recovery rate without T1 recovery. Our findings may aid clinical decisions involving the use of these drugs by encouraging their association in multimodal anesthesia or other therapeutic purposes.
\end{abstract}

Trial registration: NCT02483611 (registration date: 06-29-2015).

Keywords: Lidocaine, Magnesium sulfate, Neuromuscular blockade, General anesthesia, Hemodynamic parameters

\section{Background}

Anesthetic additive drugs, such as lidocaine and magnesium sulfate (MS), have become increasingly utilized, either alone or in combination, in general anesthesia for postoperative pain reduction, achievement of reduced and more balanced anesthetic doses, hemodynamic stabilization, and improvement of surgical conditions [1, 2]. Opioid-sparing or opioid-free anesthesia is a relatively new strategy that is increasingly being used in daily anesthesia practice [3]. A combination of lidocaine and magnesium sulfate in a multimodal opioid-sparing or even opioid-free anesthetic approach may reduce or eliminate the use of opioids in the perioperative period $[4,5]$. Drugs such as lidocaine and magnesium sulfate are frequently used in combination with neuromuscular blocking agents (NMBAs) [6], the latter of which may contribute to residual neuromuscular blockade (NMB). It is a well-known [7] and ongoing problem [8] that NMBAs have the inherent risk of residual paralysis [9], even when used alone [10]. Furthermore, residual paralysis is most likely associated with postoperative pulmonary complications, which has also been well known for many years [11] but has still not been resolved [12].

Magnesium sulfate infusion administered before anesthesia has been found to increase the speed of onset of a rocuronium-, cisatracurium- or vecuroniuminduced NMB without necessarily enhancing its duration $[13,14]$. Furthermore, magnesium sulfate infusion reestablishes a clinically relevant degree of muscle paralysis in patients who have recovered from paralysis and causes a significant, prolonged NMB when induced by a single dose of the neuromuscular-blocking drug rocuronium [15].

The effects of lidocaine on NMB are still under debate. Previous studies have shown that local anesthetics, such as lidocaine, interact with NMBAs [16-18]. More recent studies evaluating the clinical effects of lidocaine, at lower dosages, on the NMBAs cisatracurium and rocuronium have demonstrated no changes in the recovery of NMB characteristics or speed of onset [19-21].

Considering the growing perioperative clinical applications of both lidocaine and magnesium sulfate, the possibility of using these drugs in combination increases. A combination of these drugs may not only be beneficial for surgical patients regarding opioid-sparing effects but may also influence NMB characteristics and promote changes in hemodynamic parameters. The main objective was to evaluate whether the use of additional lidocaine could influence the NMB enhancement. Thus, this study's primary endpoint was the time at which spontaneous recovery of a train-of-four (TOF) ratio of $90 \%$ was achieved (complete duration). The secondary endpoints were other NMB characteristics (onset time, duration 25 , duration 95) and hemodynamic parameters.

\section{Methods}

In this prospective, randomized, double-blind, controlled trial, sixty-six patients [American Society of Anesthesiologists (ASA) physical status I to II, aged 18 to 60 years] were recruited who were scheduled for surgery (estimated surgical time greater than $90 \mathrm{~min}$, with a similar pain stimulus and no need for a continuous neuromuscular block during the surgical procedure). The exclusion criteria were patients with diseases or on medications known to interfere with neuromuscular transmission, hepatic or renal dysfunction, electrolyte abnormalities (hypokalemia, hypocalcemia and hypermagnesemia, which can potentiate blockade), allergy to drugs used in the study, a body mass index $<18$ or $>29$ kg. $\mathrm{m}^{-2}$, and expected difficulties during mask ventilation or intubation (mouth opening and head and neck movement limitations, a short thyromental and sternomental distance, and a history of difficult intubation), as well as patients who were pregnant or breastfeeding.

The patients were randomly and equally allocated into four groups (Fig. 1). Computer-generated randomization was performed, and allocation was concealed with sequentially, numbered, sealed, opaque envelopes. The seal of the envelope was broken before the induction of general anesthesia by trained study personnel not involved in the data collection. Throughout the perioperative period, care providers, patients, and research team members were blinded to the group assignment. The $\mathrm{L}$ group received $3 \mathrm{mg} . \mathrm{kg}^{-1}$ lidocaine as an IV bolus before the induction of anesthesia and $3 \mathrm{mg} \cdot \mathrm{kg}^{-1} \cdot \mathrm{h}^{-1}$ lidocaine via IV continuous infusion during the operative period, and 


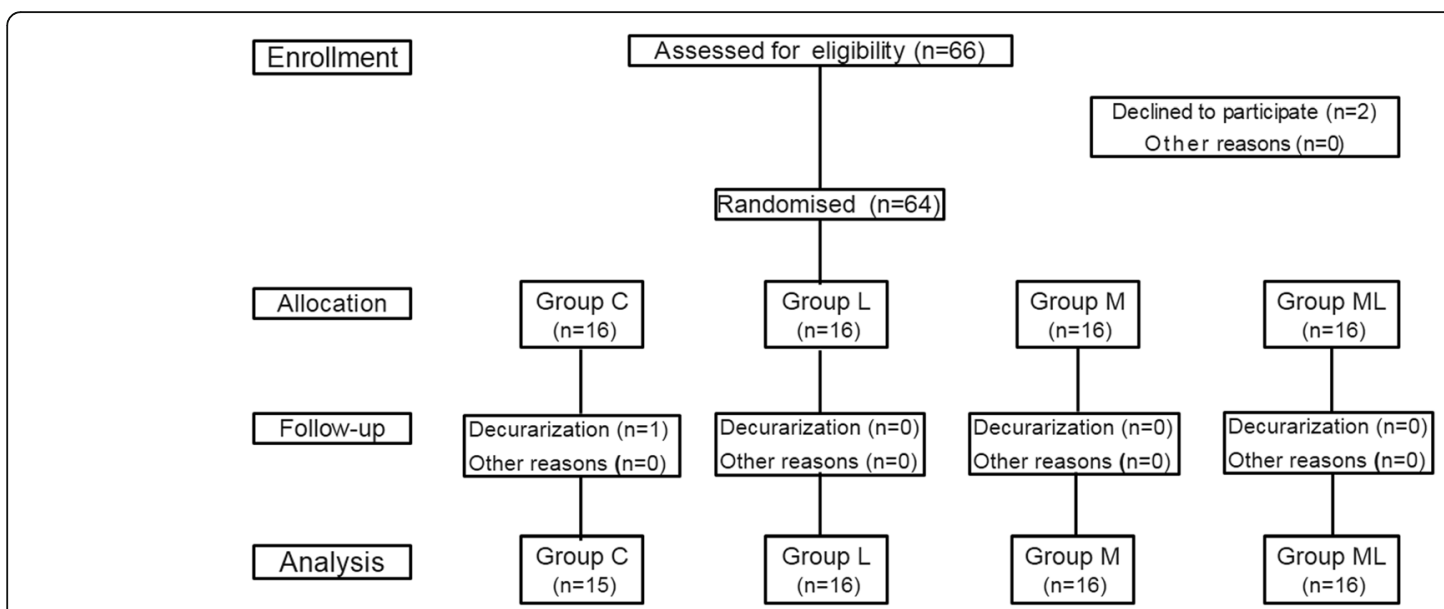

Fig. 1 Flow chart of patient participation. C: control group; M: magnesium sulfate group; ML: magnesium sulfate combined with lidocaine group

the $\mathrm{M}$ group received $40 \mathrm{mg} \cdot \mathrm{kg}^{-1}$ magnesium sulfate as an IV bolus before the induction of anesthesia and 20 $\mathrm{mg} \cdot \mathrm{kg}^{-1} \cdot \mathrm{h}^{-1}$ magnesium sulfate via IV continuous infusion during the operative period. The ML group received equal doses of magnesium sulfate combined with lidocaine at the same conditions during the operative period, and the control group received an equivalent volume of isotonic solution.

Patients were monitored using electrocardiography, noninvasive blood pressure, pulse oximetry, capnography, and body temperature (Dixtal Biomedical Industry e commerce, Brazil). Total intravenous anesthesia (TIVA) was standardized for all patients and performed without the use of benzodiazepines, using a propofol target dose (plasma targeting, Injectomat TIVA Agilia, Brazil) of $4 \mu \mathrm{g} \cdot \mathrm{mL}^{-1}$ and a remifentanil infusion of 0.5 $\mathrm{mg} \cdot \mathrm{kg}^{-1} \cdot \mathrm{min}^{-1}$. After induction, the propofol infusion target was decreased to $2.5 \mu \mathrm{g} \cdot \mathrm{mL}^{-1}$, and infusion of remifentanil was adjusted to $0.1-0.3 \mu \mathrm{g} \cdot \mathrm{kg}^{-1} \cdot \mathrm{min}^{-1}$ as needed. If systolic arterial pressure (SAP) or heart rate (HR) increased or decreased by $>30 \%$ of baseline for $>$ $60 \mathrm{~s}$, remifentanil infusion was respectively increased/decreased at $0.05 \mu \mathrm{g} \mathrm{kg}^{-1} \mathrm{~min}^{-1}$ until achieving the goal value within the range. If necessary, an ephedrine bolus (2.5 to $5 \mathrm{mg}$ ) was allowed. Hemodynamic parameters were considered stable when blood pressure and HR were within $20 \%$ of baseline values.

After induction of anesthesia and loss of consciousness, neuromuscular function was assessed by monitoring the adductor pollicis muscle via acceleromyography (AMG) with a TOF-Watch SX device (Organon Ireland Ltd., a subsidiary of Merck \& Co., Inc., Swords, Co., Dublin, Ireland) according to the neuromuscular research consensus [22].

The monitoring system was positioned on the side opposite to the blood pressure cuff and IV line. Pediatric surface electrodes (Red Dot ${ }^{\circ}, 3 \mathrm{M}$ Health
Care, Neuss, Germany) were placed on cleaned skin over the ulnar nerve on the volar side of the wrist. The transducer's position was secured by placing the thumb in a hand adapter, and a temperature sensor was fixed at the distal end of the forearm. TOF stimulation tracing was stabilized by administering TOF repetitive stimulation for $1 \mathrm{~min}$, followed by $5 \mathrm{~s}$ of $50-\mathrm{Hz}$ tetanus stimulation and another period of repetitive TOF stimulation for $3-4 \mathrm{~min}$. The CAL 2 mode was used to determine the supramaximal threshold and to calibrate the transducer of the accelerometer. After device calibration and stabilization, the mean of three TOF values was recorded in each patient and used as a reference. Complete recovery was assumed when the TOF ratio (TOFR) reached $90 \%$ of the preoperatively defined reference value (normalization). The same procedure was performed for the $\mathrm{T} 1$ measurements, assuming $\mathrm{T} 1$ response recovery as $95 \%$ of its initial value. Then, bolus doses of solutions were administered to assigned groups over $5 \mathrm{~min}$. Subsequently, single twitches were monitored to measure the onset time of cisatracurium $\left(0.15 \mathrm{mg} \cdot \mathrm{kg}^{-1}\right.$ administered over $5 \mathrm{~s}$; time point zero). Tracheal intubation was performed when TOFR reached zero. Values of $\mathrm{T} 1, \mathrm{~T} 2, \mathrm{~T} 3, \mathrm{~T} 4$, and TOFR (T4/T1); twitch responses in relation to the reference twitch response given in \%; and skin temperature were also recorded. Patients were monitored until they achieved spontaneous recovery from $\mathrm{NMB}$ (TOFR $=0.9)$. No additional cisatracurium injections were permitted. After measuring the onset time, the stimulation mode was changed to TOF $(2 \mathrm{~Hz}$, stimulus duration of $200 \mu \mathrm{s}$, square wave, 15-s intervals).

All neuromuscular monitoring data were transferred in real-time and stored on a laptop using the TOFWatch SX monitor computer program (version 2.5.INT; Organon Ltd., Dublin, Ireland). 
The following variables were measured:

(1) onset time 5 (time [min] from injection to T1 response $<5 \%$ of T0); (2) duration 25 (time [min] to spontaneous recovery of $\mathrm{T} 1$ to $25 \%$ ); (3) recovery index (time [min] between $\mathrm{T} 1=25 \%$ and $\mathrm{T} 1=75 \%$ ); (4) duration 95 (time [min] from injection to spontaneous recovery of T1 to 95\%); and (5) complete duration (time [min] from injection to spontaneous recovery of TOFR $>0.9$ ).

Hemodynamic parameters (systolic, diastolic, mean blood pressure and heart rate) were recorded and annotated at various times: M1- when the patient arrived in the operating room; M2- immediately before induction of anesthesia; M3- before the infusion of the tested solutions (saline, magnesium sulfate or magnesium sulfate associated with lidocaine); M4- five minutes after M3 (end of the infusion loading dose of test solutions); M5immediately before intubation; M6- one minute after tracheal intubation; and M7- every fifteen minutes until the end of the study. Heating elements were used to maintain the skin and central temperatures above 32 and $36^{\circ} \mathrm{C}$, respectively. All unexpected events that occurred during the study were recorded as adverse effects.

The Shapiro-Wilk test was used to assess normality. The clinical and demographic characteristics are expressed as the means $\pm \mathrm{SD}$ or medians (IQR [range]) and were compared by analysis of variance, the KruskalWallis test, or the chi-square test where appropriate. The area under the curve (AUC) was assessed to compare the hemodynamic responses between the study groups [23]. The pharmacodynamic variables (i.e., speed of onset, clinical duration, recovery rate, and complete duration) are represented as box-and-whisker plots showing the range, quartiles, and medians. The AUCs of the changes in mean arterial pressure (MAP) and HR are expressed as 95\% confidence intervals (normally distributed data). The pharmacodynamic variables were compared between the groups via the Kruskal-Wallis test, followed by Dunn's multiple comparison test. The AUCs of the changes in MAP and HR were compared between the groups by one-way ANOVA followed by the Tukey multiple comparison test. Both multiple comparison tests were used to control the type I error at 5\%. The percentages of patients who achieved a TOFR of $90 \%$ without reaching $95 \%$ recovery of the first twitch (T1) response were compared between the groups by the chi-square test. A $p$-value $<0.05$ was considered statistically significant for all outcome variables.

The primary endpoint of the present study was the time at which spontaneous recovery of a train-of-four (TOF) ratio of $90 \%$ was achieved (complete duration). Therefore, for the sample size calculation, we considered a previous study showing that magnesium sulfate prolonged the complete duration of rocuronium-induced
NMB [13]. Having chosen a significance level of $5 \%$ and a power of $80 \%$, we applied the Satterthwaite's approximation [24]. The result revealed $N=14$ patients per group, and we decided to randomized 16 patients in each group to allow for drop-outs. The statistical analysis plan has been added as a supplement file.

\section{Results}

Between 2015 and 2018, 64 patients were recruited and randomized in this study. The patient characteristics are shown in Table 1 . The vast majority of patients were ASA1, who underwent rhinoplasty and reductive mastopexy. There was no significant difference in the baseline variables between the groups. After data collection, one patient was excluded from the control group because her surgical procedure was completed in less than 90 min (Fig. 1).

Magnesium sulfate significantly prolonged all NMB recovery features, without changing the speed of onset of cisatracurium (Table 2). The addition of lidocaine to MS did not influence the cisatracurium NMB. Similar findings were observed when this drug was used alone.

The hemodynamic parameters among the study groups, evaluated by the AUCs for changes in MAP and $\mathrm{HR}$ at the six times points during anesthesia induction, are shown in Fig. $2(\mathrm{a}-\mathrm{d})$. The lidocaine group presented a significantly smaller fluctuation of MAP and HR measures during anesthesia induction (total AUC [95\% confidence interval; p]: MAP- L Group, 18.4 [0.0-41.3], compared with the $\mathrm{C}$ group, 59.9 [34.7.0-88.1], $p<$ 0.0001; compared with the $M$ group, 52.2 [32.3-72.0], $p<0.0001$; compared with the ML Group, 50.3 [32.368.4], $\mathrm{p}<0.0001$, and HR- L Group, 4.9 [0.0-15.3] compared with the C group, 17.9 [0.0-47.4], p $<0.0001$; compared with the M group, 23.0 [1.7.-44.4], $p<0.001$; compared with the ML Group, 14.9 [0.0-37.2], $p<$ 0.046). During the maintenance phase of anesthesia, the study groups exhibited a similar behavior (MAP- L Group, 1265 [583.5-1946] compared with the C group, 2256 [1529-2983], $p<0.021$; compared with the $M$ group, 1891 [1334-2448], $\mathrm{p}<0.0001$; compared with the ML Group, 1837 [1338-2335], p $<0.0001$ and HR- L Group, 533.0 [259.8-806.1] compared with the C group, 795.8 [125.2-1466], $p<0.01$; compared with the $M$

Table 1 Clinical and demographic characteristics of the patients

\begin{tabular}{llllll}
\hline & $\mathbf{C}(\boldsymbol{n}=\mathbf{1 6})$ & $\mathbf{L}(\mathbf{n}=\mathbf{1 6})$ & $\mathbf{M}(\mathbf{n}=\mathbf{1 6})$ & $\mathbf{M L}(\mathbf{n}=\mathbf{1 6})$ & $\boldsymbol{p}$ value \\
\hline Age (years) & $36 \pm 11$ & $34 \pm 9$ & $34 \pm 11$ & $32 \pm 9$ & $\mathrm{NS}$ \\
Gender(F/M) & $7 / 8$ & $8 / 8$ & $8 / 8$ & $8 / 8$ & $\mathrm{NS}$ \\
ASA PS I/II & $14 / 1$ & $14 / 2$ & $14 / 2$ & $13 / 3$ & $\mathrm{NS}$ \\
$\mathrm{BMI}\left(\mathrm{Kg} / \mathrm{m}^{2}\right)$ & $24.1 \pm 3.3$ & $24.9 \pm 3.4$ & $25.7 \pm 3.4$ & $23.2 \pm 2.6$ & $\mathrm{NS}$ \\
\hline
\end{tabular}

ASA PS American Society of Anesthesiologists phyical status, BMI body mass index, $C$ control group, $L$ lidocaine group, $M$ magnesium sulfate group, $M L$ magnesium sulfate plus lidocaine group. Values are the mean \pm S.D. 
Table 2 Neuromuscular blockade recovery characteristics

\begin{tabular}{llllll}
\hline & Control & Lidocaine & Magnesium & Magnesium + Lidocaine & $\boldsymbol{p}$ \\
\hline onset time 5 & $144(120-165[\mathrm{~min}])$ & $135(117-155[\mathrm{~min}])$ & $145(116-177[\mathrm{~min}])$ & $138(109-168[\mathrm{~min}])$ & $>0,05$ \\
duration 25 & $64(57-70[\mathrm{~min}])$ & $69(63-79[\mathrm{~min}])$ & $82(76-91[\mathrm{~min}])$ & $85(82-88[\mathrm{~min}])$ & $<0,0001$ \\
recovery index & $14(14-16[\mathrm{~min}])$ & $16(11-19[\mathrm{~min}])$ & $24(16-30[\mathrm{~min}])$ & $20(18-26[\mathrm{~min}])$ & $<0,0001$ \\
duration 95 & $87(66-90[\mathrm{~min}])$ & $88(81-101[\mathrm{~min}])$ & $109(104-126[\mathrm{~min}])$ & $113(95-117[\mathrm{~min}])$ & $<0,0001$ \\
complete duration & $89(76-99[\mathrm{~min}])$ & $104(93-107[\mathrm{~min}])$ & $119(110-129[\mathrm{~min}])$ & $123(111-140[\mathrm{~min}])$ & $<0,0001$ \\
\hline
\end{tabular}

group, 1035.0 [360.8-1708], $\mathrm{p}<0.001$; compared with the ML Group, 828.3 [294.0-1363], $p<0.0043)$.

Interestingly, the percentage of patients who achieved a TOFR of $90 \%$ without reaching T1-95\% was higher in the $\mathrm{M}$ and $\mathrm{ML}$ groups compared with the $\mathrm{C}$ and $\mathrm{L}$ groups (50.0, 56.2 and $20.0 \%, 25.0 \%$, respectively). There were no adverse events reported in this study.

\section{Discussion}

The main findings of the study showed the following: (a) intravenous lidocaine plays a significant role in the hemodynamic stability of patients under general anesthesia, without exerting any additional impact on the NMB even when combined with magnesium sulfate; (b) magnesium sulfate prolonged the time of recovery from NMB in all pharmacodynamic parameters studied; and (c) there were no differences in the speed of onset of NMB between groups.

The concept of multimodal general anesthesia has recently extended the idea of balanced anesthesia, including the use of some other additional drugs such as lidocaine, magnesium sulfate, $\beta$-blockers, and $\alpha 2$ -

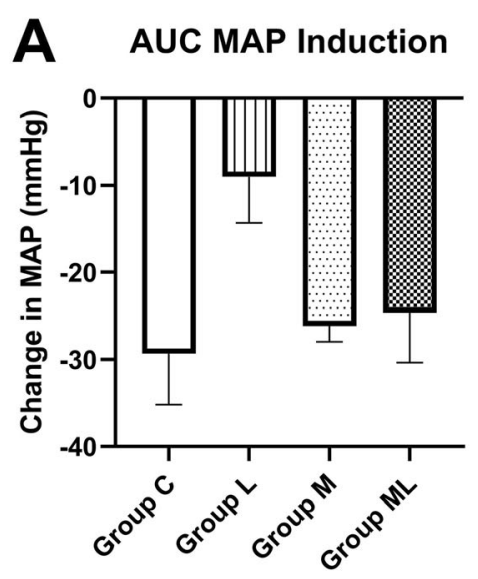

B AUC MAP Maintenance
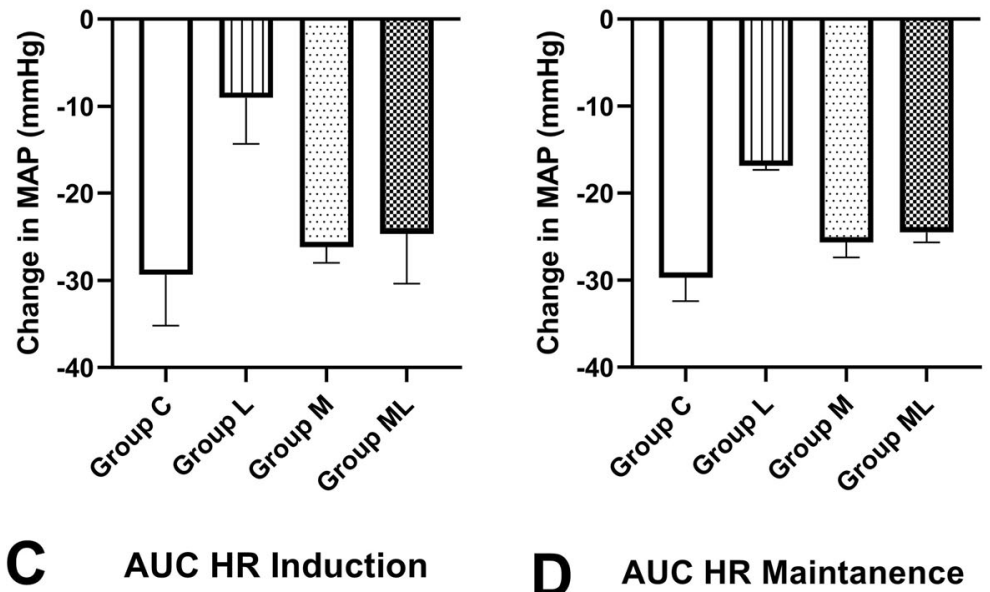

D AUC HR Maintanence
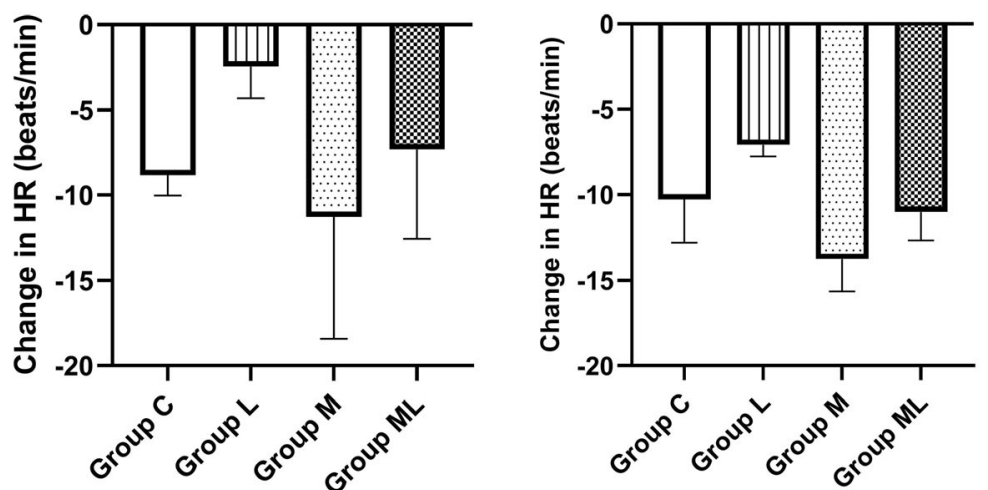

Fig. 2 Area under the curve (AUC) of hemodynamic parameters. a AUC of the mean arterial pressure (MAP) in the induction period. $\mathbf{b}$ AUC of the MAP during the maintenance period. c AUC of heart rate (HR) in the induction period. $\mathbf{d}$ AUC of HR during the maintenance period. C: control group; M: magnesium sulfate group; ML: magnesium sulfate combined with lidocaine group. Values are the mean change and $95 \%$ Cl 
agonists, which target different neuroanatomical circuits and multiple neurophysiological mechanisms [25]. The pharmacological explanation of the multimodal general anesthesia approach is based on the firmly established observation that when anesthetic drugs of different mechanisms are combined, they typically interact synergistically [26]. Lidocaine and magnesium sulfate indirectly block sympathetic effects and are well established in opioid-sparing multimodal analgesic strategies [27]. Parenteral magnesium facilitates an NMB by decreasing pre-junctional release of acetylcholine via inhibition of voltage-dependent calcium channels [28]. Typically, magnesium sulfate is administered as a bolus dose of $30-50 \mathrm{mg} \cdot \mathrm{kg}^{-1}$, followed by a maintenance dose of 6$20 \mathrm{mg} \cdot \mathrm{kg}^{-1} \cdot \mathrm{h}^{-1}$ [29]. The results of this study were in accordance with previous studies concerning the prolongation of NMB by magnesium [13, 30, 31].

Contradictory findings have been reported concerning whether the NMB onset time was reduced by magnesium sulfate. Preadministration of MS infused over 10 min has been shown to reduce the onset time of rocuronium and vecuronium [30,32], while a short period of infusion left the neuromuscular blockers' latency unchanged, in accordance with our findings [33, 34]. These findings possibly reflect differences in NMBA pharmacodynamic properties, and the higher infusion time seemed to prolong the drug's action.

Interestingly, many patients in magnesium sulfate infusion groups reached $90 \%$ of their initial TOF response without recovery of $\mathrm{T} 1$ to $95 \%$ of its original value. Staals et al [35] reported findings similar to ours after reversing rocuronium-induced NMB with sugammadex. Especially when using AMG devices, a TOFR of 0.9 seems to be associated with insufficient recovery of neuromuscular function [36, 37].

Perioperative IV administration of lidocaine varies among studies based on the dose of lidocaine bolus (1$5 \mathrm{mg} \mathrm{kg}^{-1}$ ), maintenance infusion (1-6 $\left.\mathrm{mg} \mathrm{kg}^{-1} \mathrm{~h}^{-1}\right)$ and duration of infusion [2, 38]. However, the use of doses and lidocaine as high as $5 \mathrm{mg} \cdot \mathrm{kg}^{\mathrm{k}} \mathrm{h}^{-1}$ infused for $6 \mathrm{~h}$ is reported without adverse effects [39]. Typically, the lidocaine dose used in studies assessing its impact on NMB [19-21] has been between 1.5 and $2 \mathrm{mg} \cdot \mathrm{kg}^{-1}$ (bolus) and $2 \mathrm{mg} \cdot \mathrm{kg}^{-1} \cdot \mathrm{h}^{-1}$ (maintenance), and results similar to ours were reported in these studies. Although lidocaine is widely used and is especially useful as an adjuvant during general anesthesia due to its analgesic and opioidsparing effects, few studies have systematically assessed the incidence of adverse effects or optimal dose [2]. We have considered using high doses to evaluate possible hemodynamic changes. Some studies have shown some interactions between local anesthetics and NMBAs [16$18,40]$. However, more recently, studies evaluating the clinical effects of lidocaine on cisatracurium- and rocuronium-induced $\mathrm{NMB}$ have demonstrated no changes in NMB recovery characteristics or speed of onset periods [19-21]. Corroborating these observations, in the present study, even lidocaine infusion at higher doses did not result in any additional effects on NMB and reduced MAP and HR fluctuations. Importantly, this hemodynamic stability is particularly relevant in specific conditions, such as in intracranial aneurysm management [38].

Surgical patients need to be fully awake in the recovery ward postoperatively, with acceptable pain levels and without respiratory depression, especially for patients with morbid obesity or obstructive sleep apnea [41]. It is also known that opioids present side effects, including postoperative nausea and vomiting, shivering, ileus, and urine retention [42], and can achieve both short-lasting analgesia and long-lasting hyperalgesia due to their upregulation of compensatory pronociceptive pathways [43].

Therefore, opioid-free or opioid-reduced anesthesia procedures are justified and have gained increasing popularity [44, 45]. Given these new situational demands for anesthesia and pain control protocols, evidence that lidocaine can provide hemodynamic stability during anesthesia and that its addition to magnesium sulfate does not add any side effects is valuable. These findings may encourage the use of lidocaine infusion alone or combined with magnesium sulfate in clinical practice for various therapeutic purposes, including opioid-free/sparring anesthesia with or without NMBA. The mechanisms and the precise dosage regimen for the hemodynamic stability provided by lidocaine warrant further research.

Our study has some limitations. The actual plasma concentrations of cisatracurium were not measured. However, we chose this nondepolarizing NMBA because its duration of action has low inter-individual variability. All groups have been treated with remifentanil intraoperatively and, assuming that $\mathrm{Mg}$ and lidocaine have analgesic effects, the infusion rate of remifentanil may have not been adjusted accordingly. Therefore, we cannot completely rule out a possible interference of this drug on the hemodynamic results shown in this study.

\section{Conclusions}

Intravenous lidocaine plays a significant role in the hemodynamic stability in adult patients under general anesthesia without exerting any additional impact on the $\mathrm{NMB}$, even when combined with magnesium sulfate. Aside from prolonging all NMB recovery characteristics without altering the onset speed, magnesium sulfate enhances the TOF recovery rate without T1 recovery. Our findings may aid clinical decisions involving the use of 
these drugs by encouraging their association in multimodal anesthesia or other therapeutic purposes.

\section{Abbreviations}

AMG: Acceleromyography; ASA: American Society of Anesthesiologists; AUC: Area under the curve; HR: Heart rate; MAP: Mean arterial pressure; MBP: Mean blood pressure; MS: Magnesium Sulfate; NMB: Neuromuscular blockade; NMBA: Neuromuscular blocking agent; SAP: Systolic arterial pressure; SD: Standard deviation; TIVA: Total intravenous anesthesia; TOF: Train of four: TOFR: Train of four ratio

\section{Supplementary Information}

The online version contains supplementary material available at https://doi. org/10.1186/s12871-021-01311-y.

\section{Additional file 1 .}

\section{Acknowledgments}

We thank the nursing staff of the operating rooms involved for their support in the completion of this study.

\section{Authors' contributions}

WNPG helped design the study, performed the study, analyzed the data, and wrote the manuscript. GHOP helped analyze the data and wrote the manuscript. HDDB helped analyze the data and wrote the manuscript. LVG helped design and conduct the study, analyzed the data, and wrote the manuscript. All authors have read and approved the manuscript.

\section{Funding}

The authors have no sources of funding to declare for this manuscript.

\section{Availability of data and materials}

The datasets generated and analyzed during the current study are not publicly available, as permission from participants to publicity share the dataset has not been obtained. However, these datasets are available from the corresponding author on reasonable request

\section{Declarations}

\section{Ethics approval and consent to participate}

This prospective, randomized, double-blind, controlled trial was approved by the Institutional Ethics Committee of the Hospital das Clínicas of the Faculty of Medicine of Ribeirao Preto, University of Sao Paulo, Brazil (protocol ID: 5362/2013). The study was conducted with written informed consent from the study subjects. The protocol adhered to the applicable Equator guidelines and was published by ClinicalTrials.gov (ID number NCT02483611; registration date: 06-29- 2015; https:/clinicaltrials.gov/ct2/show/NCT02483611).

\section{Consent for publication}

Not Applicable.

\section{Competing interests}

Hans D. de Boer received research grants from Merck and is treasurer of the ERAS Society.

\section{Author details}

'Department of Orthopedics and Anesthesiology, Faculty of Medicine of Ribeirao Preto, University of São Paulo, Ribeirão Preto, SP 14049900, Brazil. ${ }^{2}$ Albert Einstein College of Medicine, New York 1300 Morris Park Ave, The Bronx, NY 10461, USA. ³ Department of Anesthesiology, Pain Medicine and Procedural Sedation and Analgesia, Martini General Hospital Groningen, van Swietenplein 1, 9728, NT, Groningen, The Netherlands.

Received: 31 August 2020 Accepted: 21 March 2021 Published online: 27 March 2021

\section{References}

1. Herroeder S, Schonherr ME, De Hert SG, Hollmann MW. Magnesium-essentials for anesthesiologists. Anesthesiology. 2011;114(4):971-93.
2. Weibel S, Jokinen J, Pace NL, Schnabel A, Hollmann MW, Hahnenkamp K, et al. Efficacy and safety of intravenous lidocaine for postoperative analgesia and recovery after surgery: a systematic review with trial sequential analysis. $\mathrm{Br} J$ Anaesth. 2016;116(6):770-83.

3. Gupta S, Mohta A, Gottumukkala V. Opioid-free anesthesia-caution for a one-size-fits-all approach. Perioper Med (Lond). 2020;9:16.

4. Bafuma PJ, Nandi A, Weisberg M. Opiate refractory pain from an intestinal obstruction responsive to an intravenous lidocaine infusion. Am J Emerg Med. 2015;33(10):1544 e1543-1544.

5. Sousa AM, Rosado GM, Neto Jde S, Guimaraes GM, Ashmawi HA. Magnesium sulfate improves postoperative analgesia in laparoscopic gynecologic surgeries: a double-blind randomized controlled trial. J Clin Anesth. 2016:34:379-84.

6. Kim MH, Kim MS, Lee JH, Kim ST, Lee JR. Intravenously administered Lidocaine and magnesium during thyroid surgery in female patients for better quality of recovery after anesthesia. Anesth Analg. 2018;127(3):63541.

7. Viby-Mogensen J, Jorgensen BC, Ording H. Residual curarization in the recovery room. Anesthesiology. 1979;50(6):539-41.

8. Carvalho H, Verdonck M, Cools W, Geerts L, Forget P, Poelaert J. Forty years of neuromuscular monitoring and postoperative residual curarisation: a meta-analysis and evaluation of confidence in network meta-analysis. $\mathrm{Br} \mathrm{J}$ Anaesth. 2020;125(4):466-82.

9. Murphy GS, Brull SJ. Residual neuromuscular block: lessons unlearned. Part I: definitions, incidence, and adverse physiologic effects of residual neuromuscular block. Anesth Analg. 2010;111(1):120-8.

10. Debaene B, Plaud B, Dilly MP, Donati F. Residual paralysis in the PACU after a single intubating dose of nondepolarizing muscle relaxant with an intermediate duration of action. Anesthesiology. 2003;98(5):1042-8.

11. Beecher HK, Todd DP. A study of the deaths associated with anesthesia and surgery: based on a study of 599, 548 anesthesias in ten institutions 19481952, inclusive. Ann Surg. 1954;140(1):2-35.

12. Kirmeier E, Eriksson LI, Lewald H, Jonsson Fagerlund M, Hoeft A, Hollmann $M$, et al. Post-anaesthesia pulmonary complications after use of muscle relaxants (POPULAR): a multicentre, prospective observational study. Lancet Respir Med. 2019;7(2):129-40.

13. Czarnetzki C, Lysakowski C, Elia N, Tramer MR. Time course of rocuroniuminduced neuromuscular block after pre-treatment with magnesium sulphate: a randomised study. Acta Anaesthesiol Scand. 2010;54(3):299-306.

14. Kim SH, So KY, Jung KT. Effect of magnesium sulfate pretreatment on onset and recovery characteristics of cisatracurium. Korean J Anesthesiol. 2012; 62(6):518-23.

15. Hans GA, Bosenge B, Bonhomme VL, Brichant JF, Venneman IM, Hans PC. Intravenous magnesium re-establishes neuromuscular block after spontaneous recovery from an intubating dose of rocuronium: a randomised controlled trial. Eur J Anaesthesiol. 2012;29(2):95-9.

16. Toft $P$, Kirkegaard Nielsen H, Severinsen I, Helbo-Hansen HS. Effect of epidurally administered bupivacaine on atracurium-induced neuromuscular blockade. Acta Anaesthesiol Scand. 1990;34(8):649-52.

17. Matsuo S, Rao DB, Chaudry I, Foldes FF. Interaction of muscle relaxants and local anesthetics at the neuromuscular junction. Anesth Analg. 1978;57(5):580-7.

18. Katz RL, Gissen AJ. Effects of intravenous and intra-arterial procaine and lidocaine on neuromuscular transmission in man. Acta Anaesthesiol Scand Suppl. 1969;36:103-13.

19. Hans GA, Defresne A, Ki B, Bonhomme V, Kaba A, Legrain C, et al. Effect of an intravenous infusion of lidocaine on cisatracurium-induced neuromuscular block duration: a randomized-controlled trial. Acta Anaesthesiol Scand. 2010;54(10):1192-6.

20. Vivancos GG, Klamt JG, Garcia LV. Effects of 2 mg.kg(-)(1) of intravenous lidocaine on the latency of two different doses of rocuronium and on the hemodynamic response to orotracheal intubation. Rev Bras Anestesiol. 2011;61(1):1-12.

21. Czarnetzki C, Lysakowski C, Elia N, Tramer MR. Intravenous lidocaine has no impact on rocuronium-induced neuromuscular block. Randomised study. Acta Anaesthesiol Scand. 2012:56(4):474-81.

22. Fuchs-Buder T, Claudius C, Skovgaard LT, Eriksson LI, Mirakhur RK, VibyMogensen J. Good clinical research practice in pharmacodynamic studies of neuromuscular blocking agents II: the Stockholm revision. Acta Anaesthesiol Scand. 2007:51(7):789-808.

23. Nobre F, Mion D Jr. Is the area under blood pressure curve the best parameter to evaluate 24-h ambulatory blood pressure monitoring data? Blood Press Monit. 2005;10(5):263-70. 
24. Singer J. A simple procedure to compute the sample size needed to compare two independent groups when the population variances are unequal. Stat Med. 2001;20(7):1089-95.

25. Brown EN, Pavone KJ, Naranjo M. Multimodal general anesthesia: theory and practice. Anesth Analg. 2018;127(5):1246-58.

26. Hendrickx JF, Eger El 2nd, Sonner JM, Shafer SL. Is synergy the rule? A review of anesthetic interactions producing hypnosis and immobility. Anesth Analg. 2008;107(2):494-506.

27. Dunn LK, Durieux ME. Perioperative use of intravenous Lidocaine. Anesthesiology. 2017;126(4):729-37.

28. Dube L, Granry JC. The therapeutic use of magnesium in anesthesiology, intensive care and emergency medicine: a review. Can J Anaesth. 2003; 50(7):732-46.

29. Do SH. Magnesium: a versatile drug for anesthesiologists. Korean J Anesthesiol. 2013;65(1):4-8.

30. Fuchs-Buder T, Wilder-Smith $\mathrm{OH}$, Borgeat A, Tassonyi E. Interaction of magnesium sulphate with vecuronium-induced neuromuscular block. Br J Anaesth. 1995;74(4):405-9.

31. Pinard AM, Donati F, Martineau R, Denault AY, Taillefer J, Carrier M. Magnesium potentiates neuromuscular blockade with cisatracurium during cardiac surgery. Can J Anaesth. 2003;50(2):172-8.

32. Rotava P, Cavalcanti IL, Barrucand L, Vane LA, Vercosa N. Effects of magnesium sulphate on the pharmacodynamics of rocuronium in patients aged 60 years and older: a randomised trial. Eur J Anaesthesiol. 2013;30(10): 599-604.

33. Kussman B, Shorten G, Uppington J, Comunale ME. Administration of magnesium sulphate before rocuronium: effects on speed of onset and duration of neuromuscular block. Br J Anaesth. 1997;79(1):122-4.

34. James MF, Schenk PA, van der Veen BW. Priming of pancuronium with magnesium. Br J Anaesth. 1991;66(2):247-9.

35. Staals LM, Driessen JJ, Van Egmond J, De Boer HD, Klimek M, Flockton EA, et al. Train-of-four ratio recovery often precedes twitch recovery when neuromuscular block is reversed by sugammadex. Acta Anaesthesiol Scand. 2011;55(6):700-7.

36. Blobner M, Hunter JM, Meistelman C, Hoeft A, Hollmann MW, Kirmeier E, et al. Use of a train-of-four ratio of 0.95 versus 0.9 for tracheal extubation: an exploratory analysis of POPULAR data. Br J Anaesth. 2020;124(1):63-72.

37. Capron F, Alla F, Hottier C, Meistelman C, Fuchs-Buder T. Can acceleromyography detect low levels of residual paralysis? A probability approach to detect a mechanomyographic train-of-four ratio of 0.9 . Anesthesiology. 2004;100(5):1119-24.

38. Khan ZH, Samadi S, Ameli S, Emir Alavi C. Lidocaine as an induction agent for intracranial aneurysm surgery: a case series. Anesth Pain Med. 2016;6(1): e33250.

39. Tremont-Lukats IW, Hutson PR, Backonja MM. A randomized, doublemasked, placebo-controlled pilot trial of extended IV lidocaine infusion for relief of ongoing neuropathic pain. Clin J Pain. 2006;22(3):266-71.

40. Cardoso LS, Martins CR, Tardelli MA. Effects of intravenous lidocaine on the pharmacodynamics of rocuronium. Rev Bras Anestesiol. 2005;55(4):371-80.

41. Isono S. Obesity and obstructive sleep apnoea: mechanisms for increased collapsibility of the passive pharyngeal airway. Respirology. 2012;17(1):32-42.

42. de Boer HD, Detriche O, Forget P. Opioid-related side effects: postoperative ileus, urinary retention, nausea and vomiting, and shivering. A review of the literature. Best Pract Res Clin Anaesthesiol. 2017;31(4):499-504.

43. Angst MS, Clark JD. Opioid-induced hyperalgesia: a qualitative systematic review. Anesthesiology. 2006;104(3):570-87.

44. Koinig H, Wallner T, Marhofer P, Andel H, Horauf K, Mayer N. Magnesium sulfate reduces intra- and postoperative analgesic requirements. Anesth Analg. 1998;87(1):206-10

45. Bakan M, Umutoglu T, Topuz U, Uysal H, Bayram M, Kadioglu H, et al. Opioid-free total intravenous anesthesia with propofol, dexmedetomidine and lidocaine infusions for laparoscopic cholecystectomy: a prospective, randomized, double-blinded study. Braz J Anesthesiol. 2015;65(3):191-9.

\section{Publisher's Note}

Springer Nature remains neutral with regard to jurisdictional claims in published maps and institutional affiliations.

\section{Ready to submit your research? Choose BMC and benefit from:}

- fast, convenient online submission

- thorough peer review by experienced researchers in your field

- rapid publication on acceptance

- support for research data, including large and complex data types

- gold Open Access which fosters wider collaboration and increased citations

- maximum visibility for your research: over $100 \mathrm{M}$ website views per year

At $\mathrm{BMC}$, research is always in progress.

Learn more biomedcentral.com/submissions 